\title{
Validity, reliability and use of a Kuwait child nutrition knowledge assessment questionnaire
}

\author{
Nadine Ibrahim, ${ }^{1}$ Dima AlKaed, ${ }^{2}$ Fatima Ismail ${ }^{2}$ and Roula Barake ${ }^{3}$
}

${ }^{1}$ Health Standards Organization, Standards \& Evidence Development, Ottawa, Canada. ${ }^{2}$ Dasman Diabetes Institute, Health Standars Orgnization (HSD), Dasman, Kuwait. ${ }^{3}$ Nutrition Department, Medical Division, Dasman, Kuwait. (Correspondence to: Roula Barake: roula.barake@gmail.com).

\begin{abstract}
Background: Little is known about the nutritional knowledge of children in Kuwait and school-based nutrition interventions are scarce. No validated tool to assess the nutrition knowledge of schoolchildren in Kuwait is available.

Aims: This study determined the validity and reliability of a nutrition knowledge questionnaire in Kuwaiti primary-school children, and measured children's nutrition knowledge before and after a nutrition awareness intervention.

Methods: The questionnaire included five questions to measure nutritional knowledge. The face and content validity were assessed by nutrition and paediatric experts. To assess questionnaire reliability and nutrition knowledge, 642 schoolchildren (8-12 years) were assigned to an intervention, control or reliability group. Each group completed the questionnaire twice, one or two weeks apart. Students in the intervention group attended a nutrition knowledge presentation before completing the questionnaire the second time. Independent and paired samples $t$-tests were used to assess score differences between and within the intervention and control groups for changes in nutrition knowledge. Pearson correlation coefficients were used to measure score consistency in the reliability group.

Results: Overall, the questionnaire had good content validity and moderate to strong reliability $(r=0.44, P<0.001)$. Students in the intervention group had significantly higher mean nutritional knowledge scores after the intervention (from 3.65 (SD 1.03) to 4.20 (SD 1.02); $P=0.17$ ). Control group scores were mostly unchanged.

Conclusions: The Kuwait child nutrition knowledge questionnaire is a valid and reliable tool to assess nutritional knowledge in schoolchildren in Kuwait. Nutrition knowledge of Kuwaiti schoolchildren should be improved using age-appropriate interventions in school.
\end{abstract}

Keywords: nutrition, knowledge, schoolchildren, questionnaire, Kuwait

Citation: Ibrahim N; AlKaed D; Ismail F; Barake R. Validity, reliability and use of a Kuwait child nutrition knowledge assessment questionnaire. East Mediterr Health J. 2020;26(5):602-608. https://doi.org/10.26719/2020.26.5.602

Received: 08/02/18; accepted: 14/10/18

Copyright (C) World Health Organization (WHO) 2020. Open Access. Some rights reserved. This work is available under the CC BY-NC-SA 3.0 IGO license (https://creativecommons.org/licenses/by-nc-sa/3.o/igo).

\section{Introduction}

The prevalence of childhood obesity in Kuwait is as high as $19.9 \%$ in children between 5 and 13 years of age (1) and has exceeded $30 \%$ in adolescents $(2,3)$. Previous studies have found an association between nutritional knowledge and dietary intake, indicating that improving nutritional knowledge at an early age may help promote healthy eating patterns in children $(4,5)$. Little is known about the current levels of nutritional knowledge in young people living in Kuwait. Recent studies reported low overall nutritional knowledge in high-school and college students in Kuwait $(6,7)$. Successful school interventions have been reported in other regions, with some showing improvements in children's diets with an increase in nutritional knowledge $(8,9)$. According to the literature, one reason for failing to report consistent results is because nutritional knowledge before the design of intervention programmes has not been assessed, probably because few valid and reliable nutrition knowledge assessment tools are available (10-12). Researchers aiming to deliver successful school-based interventions to improve nutrition- al knowledge should therefore identify gaps in nutritional knowledge before designed and implementing such programmes. A nutrition knowledge questionnaire was previously validated for use with adults living in Kuwait (13). A few nutrition knowledge assessment tools for use with schoolchildren have been developed and validated in other regions $(11,14,15)$; however, none has been validated for use in children living in Kuwait or neighbouring countries. Therefore, the primary aim of our study was to develop a valid and reliable nutrition knowledge assessment tool for use in primary-school children in Kuwait. In addition, because delivering a nutrition presentation intervention is part of the validation process, our secondary aim was to evaluate children's nutritional knowledge scores before and after the presentation.

\section{Methods}

\section{Questionnaire development}

The Kuwait children nutrition knowledge questionnaire is an original self-administered questionnaire developed by two senior dietitians (see supplementary material, 
available online). It consists of a short demographics section, followed by five multiple choice questions intended to measure nutritional knowledge in children aged 8-12 years living in Kuwait. The questions were developed to assess knowledge of applied nutrition such as energy in food, understanding of nutrition labelling and assessment of portion size. Thus, one question asked about the portion equivalency of a whole fruit, two questions asked about serving size and caloric content as provided on food labels to assess skills in understanding food labels, one question assessed knowledge of healthy lifestyle recommendations, and one question assessed the ability to identify foods high in fat. The questionnaire was made available in both English and Arabic, and was administered in the main teaching language used at the schools. To assess each item's clarity and any ambiguity, face validity was assessed by a paediatric dietitian who verified the suitability of the questions by testing them on parents and their children in a clinical setting. Furthermore, the final version of the questionnaire was reviewed by an expert panel of dietitians and a consultant paediatrician to determine its content validity index (16). For the purposes of data analysis, score percentages were calculated by adding the total number of correct answers and dividing the result by the total number of questions (five), multiplied by 100.

\section{Participants}

Private and public schools in different governorates across Kuwait were invited to participate through email, telephone calls and onsite visits to schools. A convenience sample of schools $(n=11)$ was selected based on the administration's willingness to participate; all were private schools. All schoolchildren aged 8-12 years across each of the 11 schools were invited to participate. Invitation letters and parental consent forms were sent home to parents and/or guardians, and those who provided signed parental consent were included in the study. Consent was also obtained from all participating children before completing the questionnaire.

A total of 750 schoolchildren whose parents provided consent for participation were included in the study. Schoolchildren were recruited with no preference for ethnicity or gender, and both Kuwaiti and non-Kuwaiti students were included in the study. Recruitment was started and completed within the academic year of 20162017.

\section{Sample size}

A minimum of 500 participants was required to provide an $80 \%$ chance of detecting a difference between each group at $P<0.05$ and $95 \%$ confidence interval. Sample size was further confirmed by assessing similar previous work $(12,14,15)$ where sample sizes ranged between 201 and 576 children (aged 13-15 years).

\section{Data collection}

Participating schools were assigned to one of three study groups (intervention (3 schools), control (4 schools) or reliability (4 schools)) based on the schools' preference and scheduling convenience. Schools able to allocate time for the nutrition presentation were assigned to the intervention group, whereas those that were unable to do so were randomized into the control or reliability groups using simple randomization. Intervention school students completed the questionnaire at baseline $\left(\mathrm{T}_{\mathrm{o}}\right.$ ) (before the nutrition knowledge intervention) and again one week after attending a nutrition presentation $\left(\mathrm{T}_{1}\right)$. Control school students also completed the questionnaire at baseline $\left(\mathrm{T}_{0}\right)$ and again after one week later $\left(\mathrm{T}_{1}\right)$, but did not attend a nutrition presentation. Students in the reliability group completed the questionnaire at baseline $\left(\mathrm{T}_{\mathrm{o}}\right)$ and again two weeks later, without receiving a nutrition presentation. Administration of the questionnaire took place on school premises in the presence of both the teachers and the research team. The questionnaire took about 15-20 minutes for the children to complete.

\section{Nutrition intervention}

An interactive 6o-minute nutrition presentation was delivered by a senior dietitian to students in the intervention group after they had completed the questionnaire at baseline $\left(\mathrm{T}_{\mathrm{o}}\right)$. The presentation covered a number of basic nutrition topics appropriate for this age group, including: portion size and food label interpretation, relationship between healthy eating and good health, and physical activity recommendations based on the guidelines of the Centers for Disease Control and Prevention, United States of America (17). Prior to the delivery of the intervention, schools were asked whether nutrition curricula were in place. No schools included in the study delivered standardized curricula for nutrition education.

\section{Validity and reliability of the questionnaire}

Validity of the questionnaire was measured by comparing the nutritional knowledge scores of the group that received the nutrition intervention and the group that did not (control group). This was done by comparing the score differences between the intervention and control groups at $\mathrm{T}_{1}$, after the intervention group had attended a nutrition presentation that aimed to increase their nutritional knowledge. The reliability group was used to assess the test-retest reliability of the questionnaire, where scores of the same student were compared at $\mathrm{T}_{0}$ and $\mathrm{T}_{1}$, with a two-week interval between completing the questionnaire the first and second time. According to the literature, a two-week interval is short enough for children not to have gained additional nutritional knowledge and long enough to have forgotten the answers in the first attempt (18).

\section{Statistical analysis}

Demographic differences between the intervention and control groups were assessed at baseline using the independent samples t-test for continuous variables and the chi-squared test for categorical variables. Construct validity was assessed using independent samples t-tests to an- 
alyse differences in scores between the intervention and control groups at both $\mathrm{T}_{0}$ and $\mathrm{T}_{1}$. Within-group knowledge scores were also assessed using paired samples t-tests to evaluate test score differences for each group at $T_{0}$ and $\mathrm{T}$. The maximum possible score that could be achieved was 5.0 and mean scores and standard deviations (SD) were calculated for the intervention and control groups at $\mathrm{T}_{0}$ and $\mathrm{T}_{1}$ to compare overall score differences. Analysis of variance (ANOVA) was done to test for between-group differences (intervention and control) in scores by grade. Pearson correlation coefficients were used to evaluate reliability by assessing knowledge score consistency at both the first $\left(\mathrm{T}_{0}\right)$ and second $\left(\mathrm{T}_{1}\right)$ administration of the questionnaire. Only children in the reliability group $(n=$ 221) were included in the reliability analysis. All data were analysed using Stata software, version 14.0. $P<0.05$ was considered statistically significant.

\section{Ethical approval}

Ethical approval for the study was obtained from the Ethical Review Committee of the Office of Research Affairs at the Dasman Diabetes Institute, Kuwait.

\section{Results}

\section{Demographic characteristics}

A total of 642 children (mean age 10.22 (SD 1.09) years) were included in the final analysis. In all, 108 (14.4\%) were excluded as they did not complete the second question- naire at $\mathrm{T}_{1}$ because they were absent from school on the day it was given out. Of the 642 children included in the study, $294(45.8 \%)$ attended the nutrition intervention, $127(19.8 \%)$ did not (control group) and 221 (34.4\%) were in the reliability group. The sample included about the same number of boys and girls. Intervention and control groups had comparable demographic characteristics with respect to age and sex, but not school grade, nationality and residence (governorate) (Table 1). Since score differences were tested across grades, school grade was not controlled for in the analysis.

\section{Reliability and validity}

The Kuwait children nutrition knowledge questionnaire showed good content validity when assessed for efficacy by peer reviewers at the Dasman Diabetes Institute. For the content validity index review of the five items, expert ratings were highest $(\geq 80 \%)$ for clarity, level of complexity, significance in the specified content area and applicability to the target population. All five items of the questionnaire were therefore retained for the purposes of this study. Results from the test-retest reliability assessment showed that the overall questionnaire had moderate, significant reproducibility in schoolchildren between the ages of 8 and 12 years living in Kuwait $(n=221$; $r=0.44, P<0.001$ ), with mean scores remaining almost unchanged when the students completed it the first and second times (3.78 (SD 0.95) to 3.86 (SD 0.91), respectively).

\begin{tabular}{|c|c|c|c|}
\hline Variable & $\begin{array}{l}\text { Intervention groups } \\
\qquad(n=294)\end{array}$ & Control groups $(n=127)$ & P-value ${ }^{a}$ \\
\hline Age (years), mean (SD) & $10.12(1.06)$ & $10.20(1.2)$ & 0.54 \\
\hline \multicolumn{4}{|l|}{ Sex, no. (\%) } \\
\hline Female & $142(48.3)$ & $66(52.0)$ & \multirow[t]{2}{*}{0.49} \\
\hline Male & $152(51.7)$ & $61(48.0)$ & \\
\hline \multicolumn{4}{|l|}{ Nationality, no. (\%) } \\
\hline Kuwaiti & $198(67.4)$ & $62(48.8)$ & \multirow[t]{2}{*}{$<0.001$} \\
\hline Non-Kuwaiti & $96(32.6)$ & $65(51.2)$ & \\
\hline \multicolumn{4}{|l|}{ School grade, no. (\%) } \\
\hline 3 & - & $3(2.3)$ & \multirow{5}{*}{$<0.001$} \\
\hline 4 & $98(33.3)$ & $44(34.65)$ & \\
\hline 5 & $105(35.7)$ & $28(22.0)$ & \\
\hline 6 & $62(21.1)$ & $35(27.6)$ & \\
\hline 7 & $29(9.9)$ & $17(13.4)$ & \\
\hline \multicolumn{4}{|l|}{ Governorate, no. (\%) } \\
\hline Capital & $100(34.0)$ & $18(14.2)$ & \multirow{6}{*}{$<0.001$} \\
\hline Hawalli & $159(54.1)$ & $33(26.0)$ & \\
\hline Al-Farwaniya & $14(4.8)$ & - & \\
\hline Al-Ahmadi & $4(1.4)$ & $63(49.6)$ & \\
\hline Al-Jahra & $5(1.7)$ & $9(7.1)$ & \\
\hline Mubarak-Al Kabeer & $12(4.1)$ & $4(3.2)$ & \\
\hline
\end{tabular}




\section{Nutrition knowledge}

Mean overall scores of the Kuwait children nutrition knowledge questionnaire were 3.73 (SD 1.00) at baseline and 4.03 (SD 1.00) at follow-up ( $n=642$ ). A comparison of the intervention and control groups showed an increase in mean scores at retest in the children who received the intervention, which reflected an $11.0 \%$ improvement of percentage correct score (Table 2). Scores for control school students remained relatively unchanged, with only a slight improvement seen at $\mathrm{T}_{1}$ (Table 2). An assessment of score differences by grade in the intervention and control groups showed a similar trend, where students in the intervention group scored consistently higher than those in the control group at $\mathrm{T}_{1}$ across all grades (Table 2). Students in grade 6 showed the greatest improvement in scores (16.8\% improvement of percentage correct score), although grade 7 students in the intervention group had the highest score at $\mathrm{T}_{1}(4.48, \mathrm{SD} 0.63)$.

\section{Discussion}

Students who received the nutrition intervention scored significantly higher than the controls the second time both groups completed the Kuwait children nutrition knowledge questionnaire. The $11.0 \%$ score increase we found is higher than scores reported in similar studies $(14,19)$ but lower than those of others $(20,21)$. However, it is important to note that while we delivered a presentation-focused, interactive intervention, it was just one 6o-minute session. Other interventions were longer, ranging from 90 minutes to 3 years $(12,14,19-21)$, and the longer length of these interventions may explain the higher score differences some studies found. Despite its short length, the Kuwait children nutrition knowledge questionnaire includes items that cover some of the most relevant nutritional topics for this age group. The short length of the questionnaire did not appear to affect the validity of the results, as shown by the item-specific increase in correct scoring in the intervention group of schoolchildren. Children who received the nutrition intervention scored more correct answers at $\mathrm{T}_{1}$ on each item than those who did not have the intervention, and average percentage correct scores increased on the second administration $(73.0 \%$ to $84.0 \%$ ). Control scores were approximately similar at retest $(76.0 \%$ to $78.6 \%)$. These results are in line with reported values of an American study, which found that students who received the intervention scored higher at retest, while control scores also remained high but relatively unchanged (14). Researchers in South Africa also found that nutrition knowledge in the intervention group significantly improved after completing the an intervention programme (HealthKick) and, as with our study, no significant differences were observed in controls (22). The results obtained with our questionnaire are therefore similar to those observed in questionnaires that are longer and more varied in content.

Further assessment by grade showed that: intervention school students in grade 7 had the highest scores at retest; score increases differed significantly

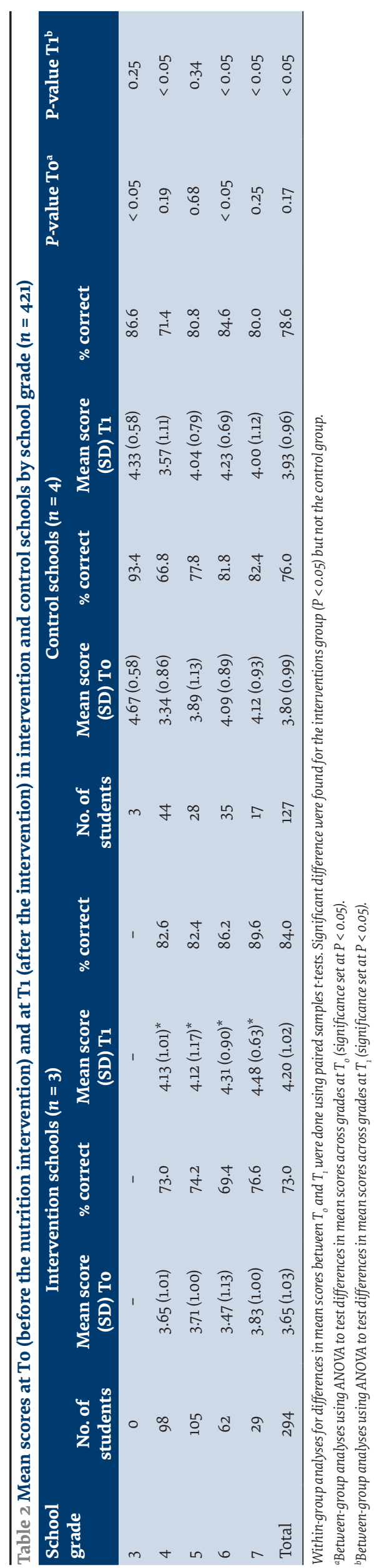


across middle-to-older grades between intervention and control students; and students in higher grades appeared to have benefitted more from the intervention. Findings from another study also show that students in higher grades had markedly higher scores on a questionnaire before and after an intervention to increase nutrition knowledge, although in this case all students were exposed to the intervention (12). Thus, while the nutrition intervention effectively increased all scores in the Kuwait children nutrition knowledge questionnaire at $\mathrm{T}$, it was especially advantageous to older children. Students in higher grades are typically more adept at understanding material but are also more heavily burdened with other school work; without an intervention, older students may disregard the importance of the questionnaire or refrain from refreshing their nutritional knowledge. This was seen in our study where control students in grade 7 scored higher than the intervention group at baseline but significantly lower at retest. In addition, within-group differences showed significant score increases for the intervention group in grades 4 to 7 . These results are more favourable than those described in a similar study where only children in grade 2 appeared to score higher at retest (12).

The moderate to strong test-retest reliability of the overall questionnaire is comparable to that reported in similarly short questionnaires (12,14). However, a longer questionnaire used by a study in Texas had stronger reliability correlations (23). Interestingly, questions from the nutrition knowledge category of the questionnaire used in the Texas study showed the weakest reproducibility $(r=0.40)$, especially for serving size and label literacy items (23). This was seen in our study, where the lowest correlations were reported in questions associated with reading nutrition labels.

Our study has several strengths. First, the Kuwait children nutrition knowledge questionnaire is the first valid and reliable nutritional knowledge assessment tool for children in Kuwait, without age or gender bias. Second, the short length and time needed to complete the questionnaire and receive the intervention made recruitment relatively easy, and the simplicity of the questions compared to other questionnaires allowed for easier comprehension. Finally, the short yet effective intervention was less time-consuming for students and was not a burden on busy school schedules. Some limitations to our study should be noted: given that all participants were recruited from private schools, the results may not be generalizable to children attending public schools in Kuwait. Moreover, randomization of intervention and control students was not done because the intervention schools were recruited based on their agreement to allocate time for the nutrition presentation. This may increase the possibility of selection bias and reduce the ability to generalize results to other populations.

\section{Conclusion}

Increasing nutritional awareness in schools is both beneficial and necessary for the health of schoolchildren. The Kuwait children nutrition knowledge questionnaire is the first valid and reliable tool for the assessment of nutritional knowledge in schoolchildren aged 8 to 12 years living in Kuwait. Results from the study, while promising, require further validation in the public-school setting. This questionnaire has the potential to identify gaps in nutritional knowledge and nutrition curricula in primary schools in Kuwait and neighbouring countries. When accompanied by a nutrition intervention, the questionnaire can be used to help develop more effective and well-designed school-based nutrition intervention programmes aiming to improve nutrition knowledge and prevent obesity-related diseases in later life. Future studies should consider testing the Kuwait children nutrition knowledge questionnaire in the general school-aged population of Kuwait by implementing the questionnaire in both public and private schools.

Funding: This study was funded by the Kuwait Foundation for the Advancement of Sciences.

Competing interests: None declared.

\section{Validité, fiabilité et utilité d'un questionnaire d'évaluation des connaissances des enfants en matière de nutrition au Koweït}

\section{Résumé}

Contexte : Peu d'informations sont disponibles sur les connaissances des enfants koweïtiens en matière de nutrition, et les interventions d'éducation nutritionnelle dans les écoles sont rares. Aucun outil validé permettant d'évaluer les connaissances des écoliers koweïtiens à cet égard n'est disponible.

Objectifs: La présente étude visait à déterminer la validité et la fiabilité d'un questionnaire d'évaluation des connaissances en matière de nutrition auprès d'écoliers du cycle primaire au Koweït, et à mesurer les connaissances des enfants à cet égard avant et après une intervention de connaissance nutritionnelle.

Méthodes : Le questionnaire comportait cinq questions visant à évaluer le niveau de connaissance nutritionnelle. La validité apparente et de contenu du questionnaire a été évaluée par des experts en pédiatrie et en nutrition. Afin de mesurer la fiabilité du questionnaire et le niveau de connaissance en matière de nutrition, 642 écoliers (âgés de 8 à 12 ans) ont été répartis en trois groupes : un groupe d'intervention, un groupe témoin et un groupe servant à garantir la fiabilité. Chaque groupe a répondu deux fois au questionnaire, à une ou deux semaines d'intervalle. Les écoliers du groupe 
d'intervention ont assisté à une présentation sur la nutrition avant de répondre une deuxième fois au questionnaire. Des tests $t$ d'échantillons appariés et indépendants ont été utilisés pour évaluer les différences de scores entre le groupe d'intervention et le groupe témoin et au sein de ces deux groupes dans le but d'interpréter l'évolution des connaissances nutritionnelles. Les coefficients de corrélation de Pearson ont été utilisés pour mesurer la cohérence des scores dans le groupe de fiabilité.

Résultats: Globalement, le questionnaire présentait une bonne validité de contenu et une fiabilité moyenne à élevée $(r=0,44, p<0,001)$. Les écoliers du groupe d'intervention avaient des scores de connaissance nutritionnelle beaucoup plus élevés suite à l'intervention (passant de 3,65 (E.T. 1,03) à 4,20 (E.T. 1,02); $p=0,17$ ). Les scores du groupe témoin étaient en grande partie restés inchangés.

Conclusions : Le questionnaire d'évaluation des connaissances des enfants koweïtiens en matière de nutrition constitue un outil valide et fiable pour mesurer le niveau de connaissance nutritionnelle des écoliers au Koweït. Des interventions adaptées à l'âge devraient être organisées dans les écoles afin d'améliorer le niveau de connaissance des écoliers koweïtiens en matière de nutrition.

$$
\begin{aligned}
& \text { صحة وموثوقية واستخدام استبيان تقييم المعرفة الغذائية للأطفال في الكويت } \\
& \text { نادين إبر اهيم، ديمة القائد، فاطمة إسماعيل، رلى بركه } \\
& \text { الخلاصة }
\end{aligned}
$$

الخلفية: لا يتو افر قدر كبير من المعلومات حوات حول مستوى المعرفة التغذوية لدى الأطفال في الكويت والتدخلات التوات التغذوية المدرسية اللازم القيام بها.

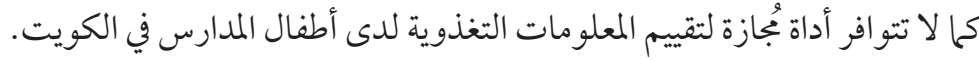

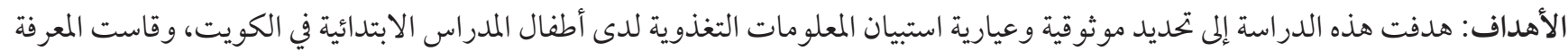

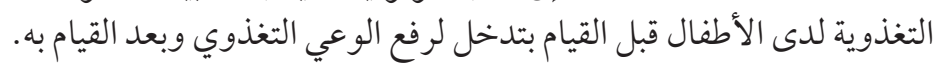

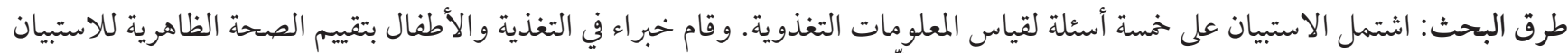

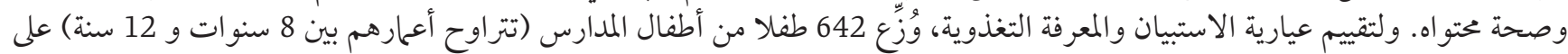

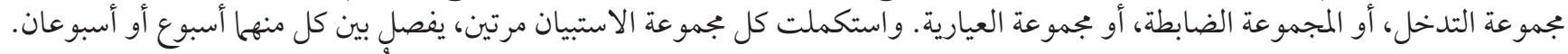

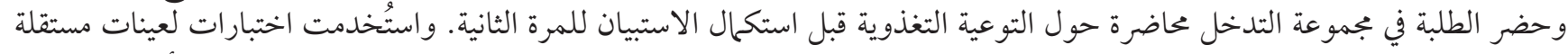

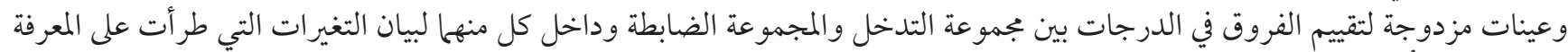

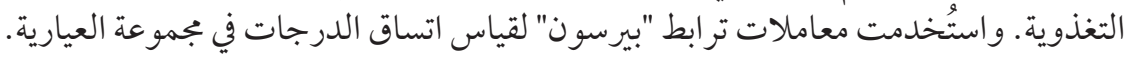

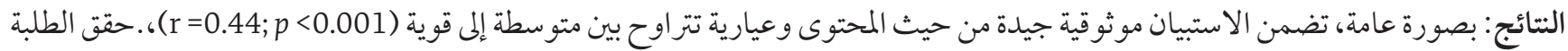

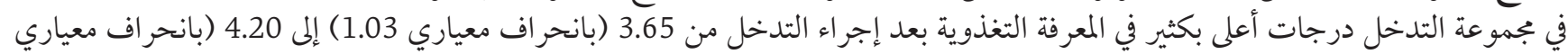

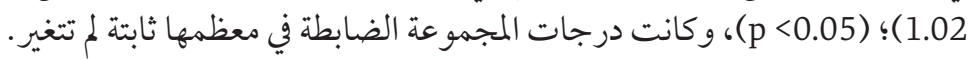

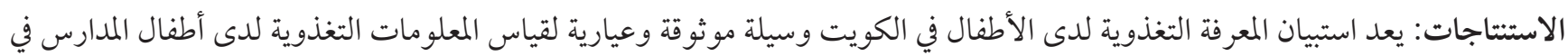

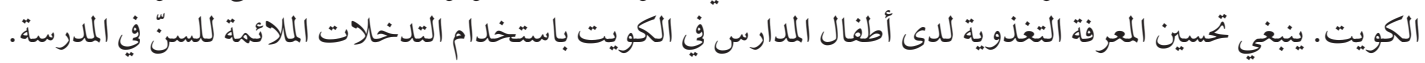

\section{References}

1. Sorkhou I, Al-Qallaf K, Al-Shamali N, Hajia A, Al-Qallaf B. Childhood obesity in Kuwait - prevalence and trends. Fam Med. 2003;35(7):463-4.

2. Mirmiran P, Sherafat-Kazemzadeh R, Jalali-Farahani S, Azizi F. Childhood obesity in the Middle East: a review. East Mediterr Health J. 2010;16(9):1009-17.

3. Elkum N, Al-Arouj M, Sharifi M, Shaltout A, Bennakhi A. Prevalence of childhood obesity in the state of Kuwait. Int J Pediatr Obes. 2016;11(6):e30-e4. https://doi.org/10.1111/ijpo.12090

4. Spronk I, Kullen C, Burdon C, O'Connor H. Relationship between nutrition knowledge and dietary intake. Br J Nutr. 2014;111(10):1713-26. https://doi.org/10.1017/Soo07114514000087

5. Choi E, Shin N, Jung E, Park H, Lee H, Song K. A study on nutrition knowledge and dietary behavior of elementary school children in Seoul. Nutr Res Pract. 2008;2(4):308-16. https://doi.org/10.4162/nrp.2008.2.4.308

6. Al-Isa A, Alfaddagh A. Nutritional knowledge among Kuwaiti college students. Health. 2014;6(05):448-53. https://doi.org/10.4236/ health.2014.65063

7. Alrefaee F, Nassar M, Aldhafiri S, Alqattan S, Mutairi AA. 432 Nutritional knowledge, attitude and practice of high school girls living in Kuwait: a pilot study. Arch Dis Child. 2012;97(Suppl 2):A127. http://doi.org/10.1136/archdischild-2012-302724.0432 
8. Waters E, de Silva-Sanigorski A, Hall BJ, Brown T, Campbell KJ, Gao Y, et al. Interventions for preventing obesity in children. Cochrane Database Syst Rev. 2011(12):CDoo1871. https://doi.org/10.1002/14651858.CDoo1871.pub3

9. Amini M, Djazayery A, Majdzadeh R, Taghdisi M-H, Jazayeri S. Effect of school-based interventions to control childhood obesity: a review of reviews. Int J Prev Med. 2015;6:68. https://doi.org/10.4103/2008-7802.162059

10. Worsley A. Nutrition knowledge and food consumption: can nutrition knowledge change food behaviour? Asia Pac J Clin Nutr. 2002;11(Suppl 3):S579-85.

11. Wilson AM, Magarey AM, Mastersson N. Reliability and relative validity of a child nutrition questionnaire to simultaneously assess dietary patterns associated with positive energy balance and food behaviours, attitudes, knowledge and environments associated with healthy eating. Int J Behav Nutr Phys Act. 2008;5(1):5. https://doi.org/10.1186/1479-5868-5-5

12. Reynolds JS, Treu JA, Njike V, Walker J, Smith E, Katz CS, et al. The validation of a food label literacy questionnaire for elementary school children. J Nutr Educ Behav. 2012;44(3):262-6. https://doi.org/10.1016/j.jneb.2011.09.006

13. Alkaed D, Ibrahim N, Ismail F, Barake R. Validity and reliability of a nutrition knowledge questionnaire in an adult student population. J Nutr Educ Behav. 2018;50(7):718-23. https://doi.org/10.1016/j.jneb.2018.03.012

14. Gower JR, Moyer-Mileur LJ, Wilkinson RD, Slater H, Jordan KC. Validity and reliability of a nutrition knowledge survey for assessment in elementary school children. J Am Diet Assoc 2010;110(3):452-6. https://doi.org/10.1016/j.jada.2009.11.017

15. Vereecken C, De Pauw A, Van Cauwenbergh S, Maes L. Development and test-retest reliability of a nutrition knowledge questionnaire for primary-school children. Public Health Nutr. 2012;15(09):1630-8. https://doi.org/10.1017/S1368980012002959

16. Polit DF, Beck CT. The content validity index: are you sure you know what's being reported? Critique and recommendations. Res Nurs Health. 2006;29(5):489-97. https://doi.org/10.1002/nur.20147

17. 2008 Physical activities guidelines for Americans. Washington (DC):US Department of Health and Human Services; 2008 (https://health.gov/sites/default/files/2019-09/paguide.pdf, accessed 21 February; 2020).

18. Parmenter K, Wardle J. Evaluation and design of nutrition knowledge measures. J Nutr Educ Behav. 2000;32(5):269-77. https:// doi.org/10.1016/S0022-3182(00)70575-9

19. Jacobs KL, Mash B, Draper CE, Forbes J, Lambert EV. Evaluation of a school-based nutrition and physical activity programme for Grade 4 learners in the Western Cape province. S Afr Fam Pract. 2013;55(4):391-7.

20. Warren JM, Henry CJ, Lightowler HJ, Bradshaw SM, Perwaiz S. Evaluation of a pilot school programme aimed at the prevention of obesity in children. Health Promot Int. 2003;18(4):287-96. http://doi.org/10.1093/heapro/dag402

21. Katz DL, Katz CS, Treu JA, Reynolds J, Njike V, Walker J, et al. Teaching healthful food choices to elementary school students and their parents: the nutrition detectives program. J Sch Health 2011;81(1):21-8. https://doi.org/10.1111/j.1746-1561.2010.00553.x

22. de Villiers A, Steyn NP, Draper CE, Hill J, Gwebushe N, Lambert EV, et al. Primary school children's nutrition knowledge, self-efficacy, and behavior, after a three-year healthy lifestyle intervention (HealthKick). Ethn Dis. 2016;26(2):171-80. https://doi. org/10.18865/ed.26.2.171

23. Hoelscher DM, Day RS, Kelder SH, Ward JL. Reproducibility and validity of the secondary level school-based nutrition monitoring student questionnaire. J Am Diet Assoc. 2003;103(2):186-94. https://doi.org/10.1053/jada.2003.50031 